$09 ; 15$

\title{
Двухканальный лазерный монитор для наблюдения процессов высокотемпературного горения нанопорошков металлов
}

\author{
(С) Ф.А. Губарев ${ }^{1}$, А.В. Мостовщиков ${ }^{1,2}$, А.П. Ильин ${ }^{1}$, Л. Ли ${ }^{3}$, А.И. Федоров ${ }^{4}$, Е.Ю. Буркин ${ }^{1}$, \\ В.В. Свиридов ${ }^{1}$ \\ ${ }^{1}$ Томский политехнический университет, Томск, Россия \\ ${ }^{2}$ Томский государственный университет систем управления и радиоэлектроники, Томск, Россия \\ ${ }^{3}$ Liaoning Technical University, Huludao, China \\ ${ }^{4}$ Институт оптики атмосферы им. В.Е. Зуева СО РАН, Томск, Россия \\ E-mail: gubarevfa@tpu.ru
}

Поступило в Редакцию 22 октября 2020 г.

В окончательной редакции 27 декабря 2020 г.

Принято к публикации 28 декабря 2020г.

\begin{abstract}
Представлен лазерный монитор с двумя каналами получения изображений на основе двух усилителей яркости и двух цифровых камер, позволяющий визуализировать поверхность нанопорошков металлов во время горения одновременно в двух областях образца или в одной области с различным увеличением. Задержка между импульсами излучения усилителей яркости задается таким образом, чтобы излучение одного усилителя яркости не оказывало влияния на изображение, формируемое другим усилителем яркости. Предлагаемая техника эксперимента позволяет исследовать поверхность образцов порошковых материалов во время высокотемпературного горения, сопровождающегося интенсивным свечением и разлетом продуктов сгорания. Применение двухканальной визуализации дает возможность более детального исследования поверхности горящего образца, в частности исследования неоднородности процесса горения.
\end{abstract}

Ключевые слова: лазерный монитор, усилитель яркости, высокотемпературное горение, нанопорошок металла, генератор импульсов.

DOI: 10.21883/PJTF.2021.07.50798.18593

Высокотемпературное горение смесей нано- и микропорошков металлов на основе алюминия, протекающее в воздухе при атмосферном давлении, является широко используемым и перспективным методом получения керамических и высокоэнергетических материалов на основе нанопорошков металлов [1-3]. Температура при горении нанопорошков металлов может превышать $2000 \mathrm{~K}$, а горение может сопровождаться интенсивным свечением и разлетом продуктов сгорания, что создает сложности при прямом наблюдении процесса, в том числе с использованием скоростных видеокамер [4-6]. Применение лазерных методов исследования, таких как лазерная подсветка и лазерный мониторинг, открывает возможность исследования поверхности горящих смесей нанопорошков металлов сквозь интенсивное свечение [4-9]. В работах [6-8] с использованием лазерного монитора на парах бромида меди нами отмечаются значительные вариации скорости распространения волн горения по поверхности образца, которые обусловлены флуктуационным характером горения нанопорошков. Частным случаем является лазерное инициирование, при котором распространение горения в области инициирования и в соседних областях может существенно различаться [9].

В связи с этим целью настоящей работы является разработка двухканального лазерного монитора для одновременного изучения поверхности нанопорошков металлов во время горения в двух областях с возмож- ностью исследования одной области образца с различным увеличением.

Предлагаемый в настоящей работе двухканальный лазерный монитор состоит из двух усилителей яркости на парах бромида меди (BA1, ВА2), излучение которых синхронизовано во времени. Схема данной реализации представлена на рис. 1. Принцип организации синхронной работы усилителей яркости аналогичен использованному в системе задающий генератор-усилитель мощности (МОПА-система) [10-13]. Типовой схемой накачки двух активных элементов в МОПА-системе является схема с двумя отдельными синхронизированными тиратронными генераторами импульсов, что обусловлено необходимостью получения высокой мощности генерации. При работе с нанопорошками металлов следует принимать во внимание вероятность их неконтролируемого воспламенения под действием освещающего излучения лазерного монитора. При исследовании нанопорошков металлов мощность излучения, освещающего область наблюдения, не должна превышать $50 \mathrm{~mW}$. Это значение было получено нами экспериментально в традиционной схеме лазерного монитора при использовании объектива с фокусным расстоянием $2 \mathrm{~cm}$. Поэтому для построения лазерной системы в работе использовались активные элементы на парах бромида меди с малой мощностью сверхизлучения, аналогичные использованным ранее в работах [5-8] (14 mW) и [9] $(22 \mathrm{~mW})$. Указанные значения мощности измерены в 


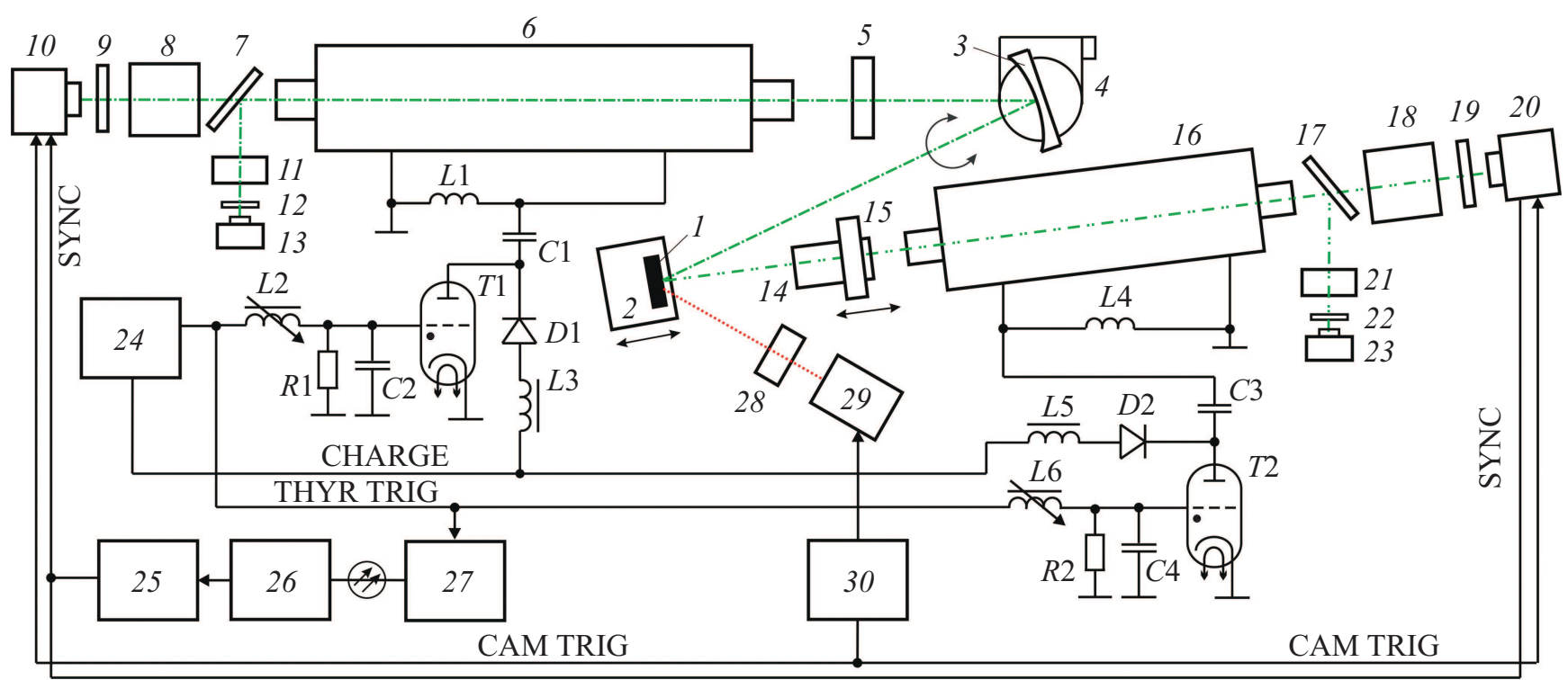

Рис. 1. Схема двухканального лазерного монитора. 1 - объект исследования; 2, 14 - линейные трансляторы; 3 - вогнутое зеркало; 4 - поворотная платформа; $5,11,15,21,28$ - линзы; 6 - усилитель яркости ВА1; 7,17 - нейтральные светофильтры; 8, 18 - объективы; 9, 19 - узкополосные светофильтры $(510 \pm 5 \mathrm{~nm}) ; 10$ - скоростная камера HSC1; 12, 22 - диффузоры; 13, 23 - фотодиоды; 16 - усилитель яркости BA2; 20 - скоростная камера HSC2; 24 - импульсный источник питания; 25 генератор синхроимпульсов; 26, 27 - оптические преобразователи; 29 - инициирующий лазер; 30 - генератор одиночных импульсов; $T 1, T 2$ - тиратроны; $L 1, L 4$ - шунтирующие индуктивности; $L 2, L 6$ - ферровариометры; $L 3, L 5-$ зарядные индуктивности; $C 1, C 3$ - накопительные конденсаторы; $C 2, C 4-$ обостряющие конденсаторы; $R 1, R 2$ - согласующие резисторы; $D 1, D 2$ - зарядные диоды.

области наибольшей четкости изображения, т.е. соответствуют мощности излучения, освещающего объект наблюдения в ходе исследования. Газоразрядные трубки имели независимую стабилизацию температуры активной области и контейнеров с рабочим веществом.

Каждый канал двухканального источника высоковольтных импульсов для накачки усилителей яркости реализован на основе схемы с импульсным зарядом накопительной емкости [14]. Накопительная емкость в разрядном контуре BA1 составляла $1000 \mathrm{pF}$, в разрядном контуре ВА2 - $680 \mathrm{pF}$. Емкости заряжались до одинакового напряжения $\sim 5.2 \mathrm{kV}$ с частотой $16 \mathrm{kHz}$. Заряд осуществлялся от одного двухтактного преобразователя с входным стабилизированным напряжением. Коммутирование накопительных емкостей на газоразрядных трубках осуществлялось посредством тиратронов ТГИ1-1000/25. Импульсы запуска тиратронов формировались схемой на основе импульсного трансформатора и подавались на тиратроны через ферровариометры, позволяющие варьировать задержку между импульсами излучения усилителей в диапазоне от -50 до $+50 \mathrm{~ns}$ (знак ,Плюс“" показывает, что сначала идет излучение BA1, затем излучение ВА2, а знак „минус“ - наоборот, сначала ВА2, затем ВА1) с джиттером $\leqslant 2$ ns. Взаимное положение импульсов излучения контролировалось фотодиодами 13 и 23 (Thorlabs DET10A/M) и осциллографом Tektronix TDS 3054C. В отличие от схемы запуска на основе тиратрона и двух импульсных трансформаторов [13] в настоящей работе использовался транзисторный ключ и один трансформатор, к которому подключались оба ферровариометра.

Предлагаемый двухканальный лазерный монитор (рис. 1) формировал изображение независимо двумя проекционными системами. Проекционная система с усилителем ВА1 построена по схеме, состоящей из вогнутого зеркала с радиусом кривизны $3 \mathrm{~m}$ и собирающей линзы с фокусным расстоянием $1 \mathrm{~m}[6,8,9]$. Область наблюдения составляла $6 \mathrm{~mm}$ в диаметре при расстоянии $50 \mathrm{~cm}$ от вогнутого зеркала до объекта. Усилитель ВА1 имел диаметр активной области $3 \mathrm{~cm}$ при длине $60 \mathrm{~cm}$. Проекционная система с ВА2 построена по традиционной схеме лазерного монитора, в которой изображение формировалось линзой. Усилитель ВА2 имел диаметр активной области $1.5 \mathrm{~cm}$ и длину $50 \mathrm{~cm}$. Изображения записывались двумя скоростными камерами Photron Fastcam SA1 (HSC1, монохромная) и Phantom Miro C110 (HSC2, цветная), работающими с разрешением $1024 \times 1024$ pixels и частотой $500 \mathrm{~Hz}$. Синхронизация обеих камер осуществлялась одними сигналами SYNC и CAM TRIG.

На рис. 2, $a$ показаны изображения тестового объекта - медной сетки с шагом $0.3 \mathrm{~mm}$ - при одновременном наблюдении двумя проекционными системами. Под одновременным наблюдением понимается регистрация обеими скоростными камерами HSC1 и HSC2 в пределах одного межимпульсного периода усилителей яркости $(62.5 \mu \mathrm{s})$. Линза 15 (рис. 1), формирующая изображение, имела фокусное расстояние $8 \mathrm{~cm}$. Полученные резуль- 

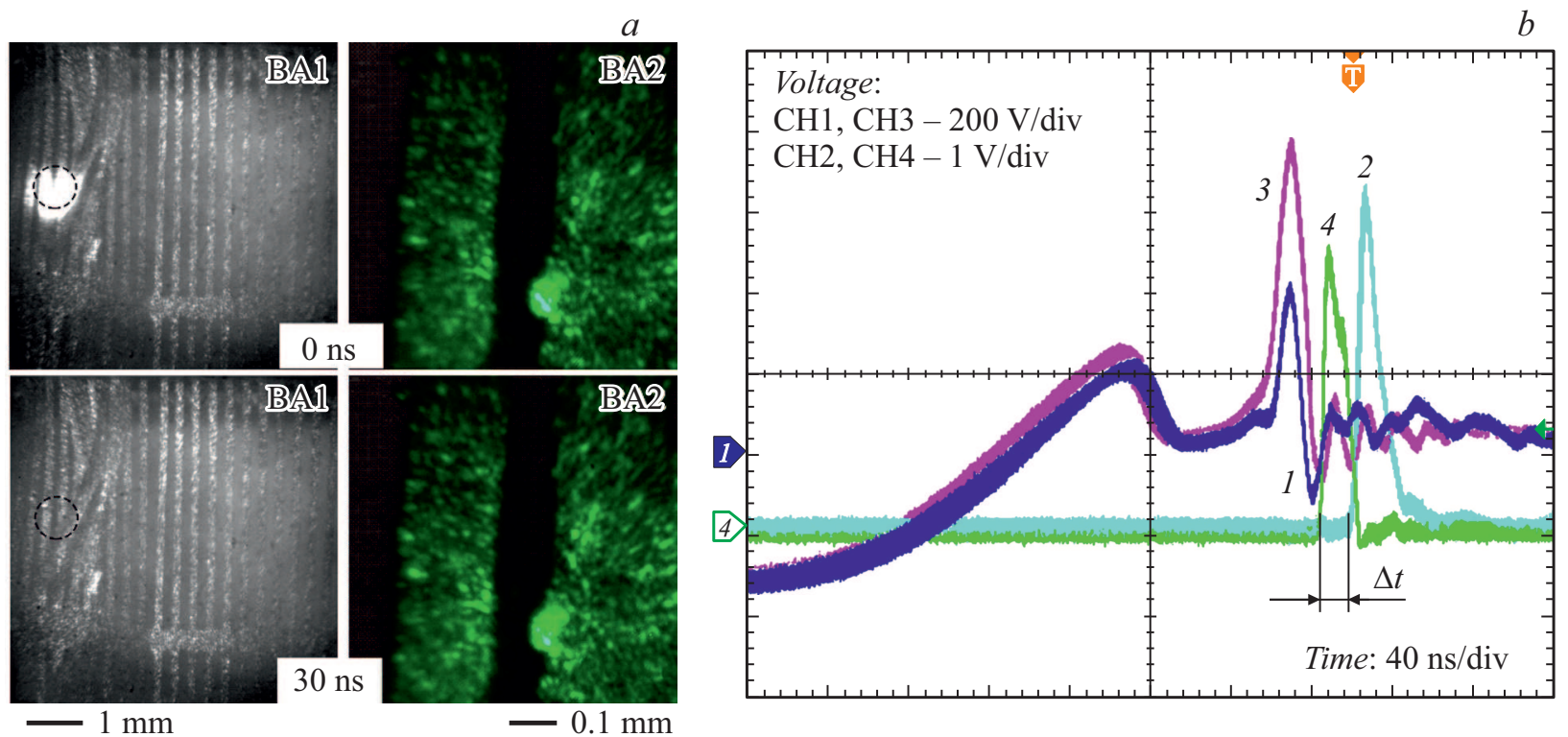

Рис. 2. Изображения тестового объекта при различной задержке между импульсами излучения усилителей яркости $\Delta t(a)$ и осциллограммы напряжений на сетках тиратронов и выходах фотодиодов при $\Delta t=16 \mathrm{~ns}(b)$. Штриховой линией на изображениях ВА1 выделена область наблюдения ВА2. 1 - напряжение на сетке тиратрона $T 1,2$ - выходное напряжение фотодиода 13 (излучение BA1), 3 - напряжение на сетке тиратрона T2, 4 - выходное напряжение фотодиода 23 (излучение ВА2).
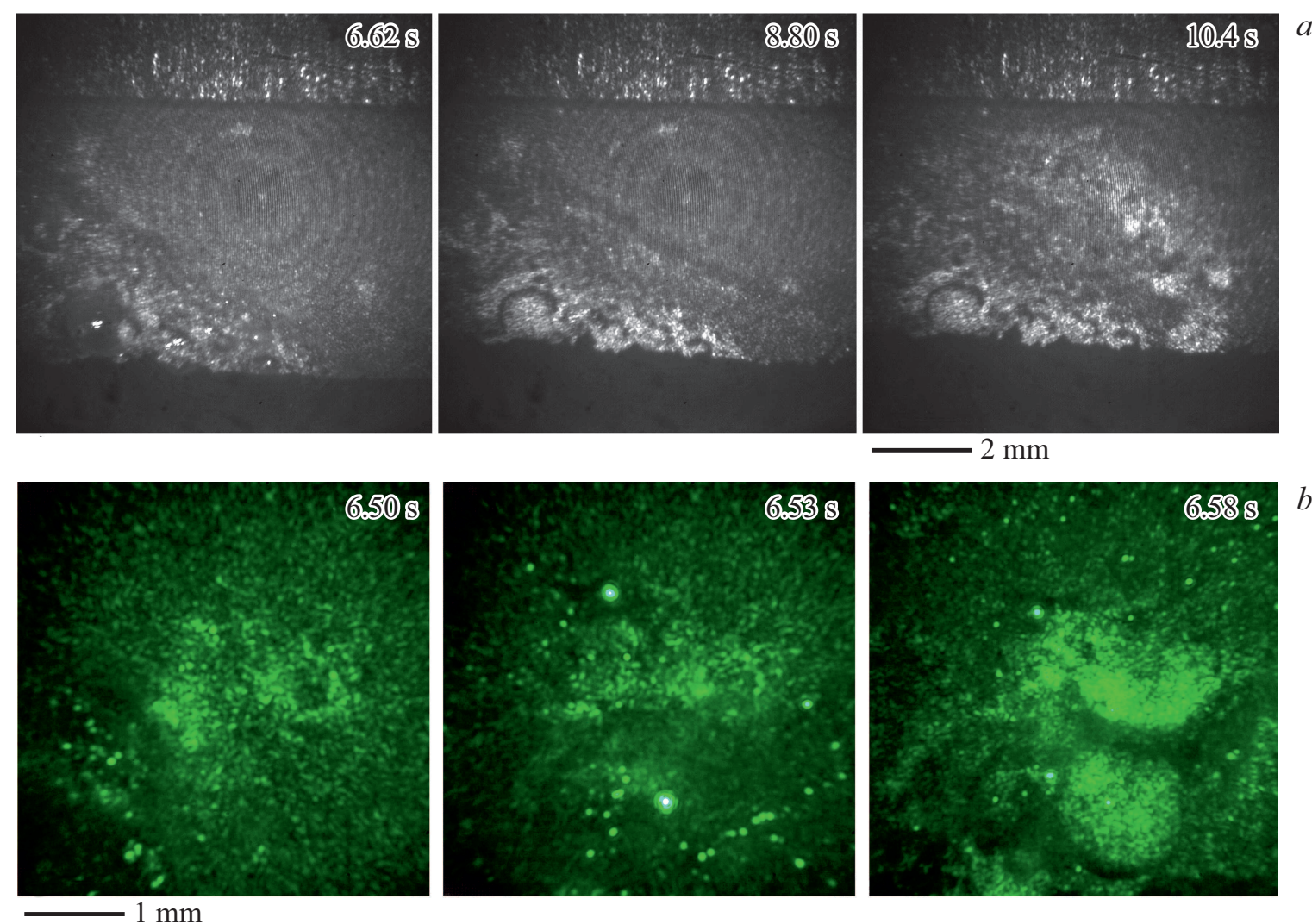

Рис. 3. Изображения поверхности смеси нанопорошков nano-Al- $\mu$-Al-nano-Fe в разные моменты во время горения, полученные с использованием двухканального лазерного монитора. $a-\mathrm{BA} 1, b-\mathrm{BA} 2$.

таты показывают, что усилители яркости не оказывают взаимного влияния при задержках импульсов накачки \pm 30 ns. Задержка 30 ns превышает длительность импуль- са сверхизлучения для рассматриваемых усилителей, которая составляет 20-25 ns (рис. 2,b). При задержке возбуждения ВА2 по отношению к BA1 более чем 
на $>20 \mathrm{~ns}$ усиление ВА1 приходится на время, когда активная среда ВА2 еще не излучает. При меньших задержках сверхизлучение ВА2 приходится на время существования инверсии в активной среде ВА1 и приводит к существенному увеличению яркости изображений BA1 в области, освещаемой ВА2. В то же время излучение BA1 не оказывает заметного влияния на изображения, формируемые ВА2, так как в зеркальной схеме плотность мощности излучения, освещающего поверхность объекта, в $\sim 50$ раз меньше, чем в случае короткофокусной схемы.

Возможности предложенного двухканального лазерного монитора исследовались при наблюдении горения смеси нанопорошков алюминия и железа с микропорошком алюминия nano-Al- $\mu$-Al-nano-Fe (соотношение 30/30/40\%). Образец смеси нанопорошков размером $20 \times 5 \times 3 \mathrm{~mm}$ размещался на алюминиевой пластине. Горение инициировалось диодным лазером с длиной волны $660 \mathrm{~nm}$ и средней мощностью $2 \mathrm{~W}$. Линза 15 (рис. 1) имела фокусное расстояние $50 \mathrm{~cm}$. На рис. 3 приведены кадры видеозаписей, выполненных одновременно двумя скоростными камерами. Интерференционные кольца присутствовали только на изображении Photron Fastcam SA1 и не наблюдались при использовании других камер. Области наблюдения граничили друг с другом, но не пересекались. Горение проходило слева направо: сначала область наблюдения ВА2, затем область наблюдения BA1. Как следует из представленных данных, двухканальный лазерный монитор позволяет исследовать горение одновременно в двух областях образца, при этом увеличение каждого канала может быть различным. Также различной может быть и скорость видеозаписи.

Таким образом, в работе впервые реализован двухканальный лазерный монитор, который позволяет практически одновременно (в пределах одного межимпульсного периода усилителя яркости) наблюдать горение образца в одной области с различным увеличением и пространственным разрешением или одновременно в двух различных областях с одинаковым или различным увеличением и пространственным разрешением.

С использованием предложенного метода исследования реализуется режим сдвоенных кадров с временны́м разрешением $30 \mathrm{~ns}$. Взаимное влияние излучения усилителей яркости исключается путем задержки импульсов накачки на время, превышающее время существования инверсии в активной среде.

\section{Конфликт интересов}

Авторы заявляют, что у них нет конфликта интересов.

\section{Список литературы}

[1] A.A. Gromov, U. Teipel, Metal nanopowders: production, characterization, and energetic applications (Wiley-VCH, Weinheim, 2014).
[2] А.А. Громов, Т.А. Хабас, А.П. Ильин, Е.М. Попенко, А.Г. Коротких, В.А. Архипов, А.А. Дитц, Ю.И. Строкова, Л.О. Толбанова, Горение нанопорошков металлов (Дельтаплан, Томск, 2008).

[3] Д. Сандарам, В. Янг, В.Е. Зарко, Физика горения и взрыва, 51 (2), 37 (2015).

[4] M.L. Pantoya, J.J. Granier, Propellants Explos. Pyrotech., 30 (1), 53 (2005).

[5] F.A. Gubarev, M.S. Klenovskii, L. Li, A.V. Mostovshchikov, A.P. Ilyin, Opt. Pura Apl., 54 (4), 51003 (2018).

[6] L. Li, A.V. Mostovshchikov, A.P. Ilyin, P.A. Antipov, D.V. Shiyanov, F.A. Gubarev, Proc. Combustion Inst., in press (2020). https://doi.org/10.1016/j.proci.2020.08.048

[7] L. Li, A.P. Ilyin, F.A. Gubarev, A.V. Mostovshchikov, M.S. Klenovskii, Ceram. Int., 44 (16), 19800 (2018).

[8] L. Li, A.V. Mostovshchikov, A.P. Ilyin, P.A. Antipov, D.V. Shiyanov, F.A. Gubarev, J. Appl. Phys., 127 (19), 194503 (2020).

[9] Ф.А. Губарев, S. Kim, L. Li, А.В. Мостовщиков, А.П. Ильин, Приборы и техника эксперимента, № 3, 96 (2020).

[10] А.Г. Григорьянц, М.А. Казарян, Н.А. Лябин, Лазеры на парах меди: конструкция, характеристики и применения (Физматлит, М., 2005).

[11] D.N. Astadjov, L.I. Stoychev, S.K. Dixit, S.V. Nakhe, N.V. Sabotinov, IEEE J. Quant. Electron., 41 (8), 1097 (2005).

[12] F.A. Gubarev, V.O. Troitskiy, M.V. Trigub, V.B. Sukhanov, Opt. Commun., 284 (10-11), 2565 (2011).

[13] М.В. Тригуб, Н.А. Васнев, Г.С. Евтушенко, В.А. Димаки, Приборы и техника эксперимента, № 1, 30 (2019).

[14] Е.Ю. Буркин, О.А. Кожемяк, Приборы и техника эксперимента, № 2, 91 (2016). 